\title{
Flautistas, bagels y tortillas: la vida secreta de ratas y ratones
}

\author{
Gloria Tapia Ramírez y Aarón Hernández Núñez
}

\section{Resumen}

Ratas y ratones forman parte del imaginario de la humanidad. Muchos son los mitos que giran en torno a su aspecto, hábitos o estadios de desarrollo. Han sido tratados como deidades por algunas culturas y despreciados por muchas otras. No obstante, han acompañado a la humanidad a lo largo de su historia y comparten un lazo común, incluso en aspectos de salud pública. Este texto recopila datos sobre muchos de los mitos acerca de las ratas y ratones y los clarifica con información científica reciente; asimismo, explica su papel en los ecosistemas naturales y en la salud humana.

Palabras clave: roedores, sinantropía, roedores silvestres, enfermedades.

\section{Pied PIPERS, BAGeLS AND tORTILlas: the SECRET life of RATS AND RODENTS}

\begin{abstract}
Rats and mice are highly integrated in the human imagery. There are a lot of myths and legends around their habits and their relationships with other animals. Some cultures think about them as deities; others, consider them as despicable animals. Rats and mice have lived with humanity throughout history, and they shared a common bond, even in public health aspects. In this text, we compiled data about the myths of rodents and clarify them with current scientific information. Also, we explain the role of rodents in the natural ecosystems and their very important role in human health.
\end{abstract}

Keywords: rodents, synanthropy, wild rodents, diseases.

Recepción: 13/01/2021. Aprobación: 13/04/2021. http://doi.org/10.22201/cuaieed.16076079e.2021.22.4.5 
"Flautistas, bagels y tortillas: la vida secreta de ratas y ratones"

Gloria Tapia Ramírez y Aarón Hernández Núñez

Vol. 22, Núm. 4, julio-agosto 2021

Revista Digital Universitaria

Gloria Tapia Ramírez

tapiaramglo@gmail.com

orcid.org/0000-0002-8991-9640

Bióloga egresada del Instituto Politécnico Nacional (IPN), doctorante en El Colegio de la Frontera Sur en Chiapas. Su principal objeto de estudio son los roedores y su relación con las características ambientales. Ha desarrollado este tema desde hace diez años.

\section{Aarón Hernández Núñez}

aharhon@gmail.com

Twitter: @D_insignis

facebook.com/aharhon.nunez

Es un biólogo mexicano, egresado de la Universidad Autónoma Metropolitana (UAM), Unidad Xochimilco. Su principal interés es el estudio de la fauna silvestre y sus parásitos. Actualmente es estudiante del Doctorado en Ciencias Marinas en el Cinvestav, Unidad Mérida.

\section{El flautista de Hamelin}

En una cálida tarde de verano durante la Edad Media, en un pequeño pueblo de Alemania, un nutrido grupo de ratas seguía a un hombre que tocaba entusiastamente una flauta. Iban una tras otra, siguiéndolo como hipnotizadas por las notas que salían del instrumento. Sin saberlo, él las conducía al río, donde conocerían un triste final, pues morirían ahogadas para beneplácito de los habitantes de Hamelin (Grimm y Grimm, 2000).

Así se desarrolla parte de una de las fábulas más conocidas de los hermanos Grimm, en la cual, los pobladores de Hamelin confiaron en que las ratas que los habían importunado por semanas, tenían la capacidad de escuchar la música de un flautista y seguirlo hasta su muerte (ver imagen 1).

Imagen 1. Postal que represental al flautista de Hamelin.

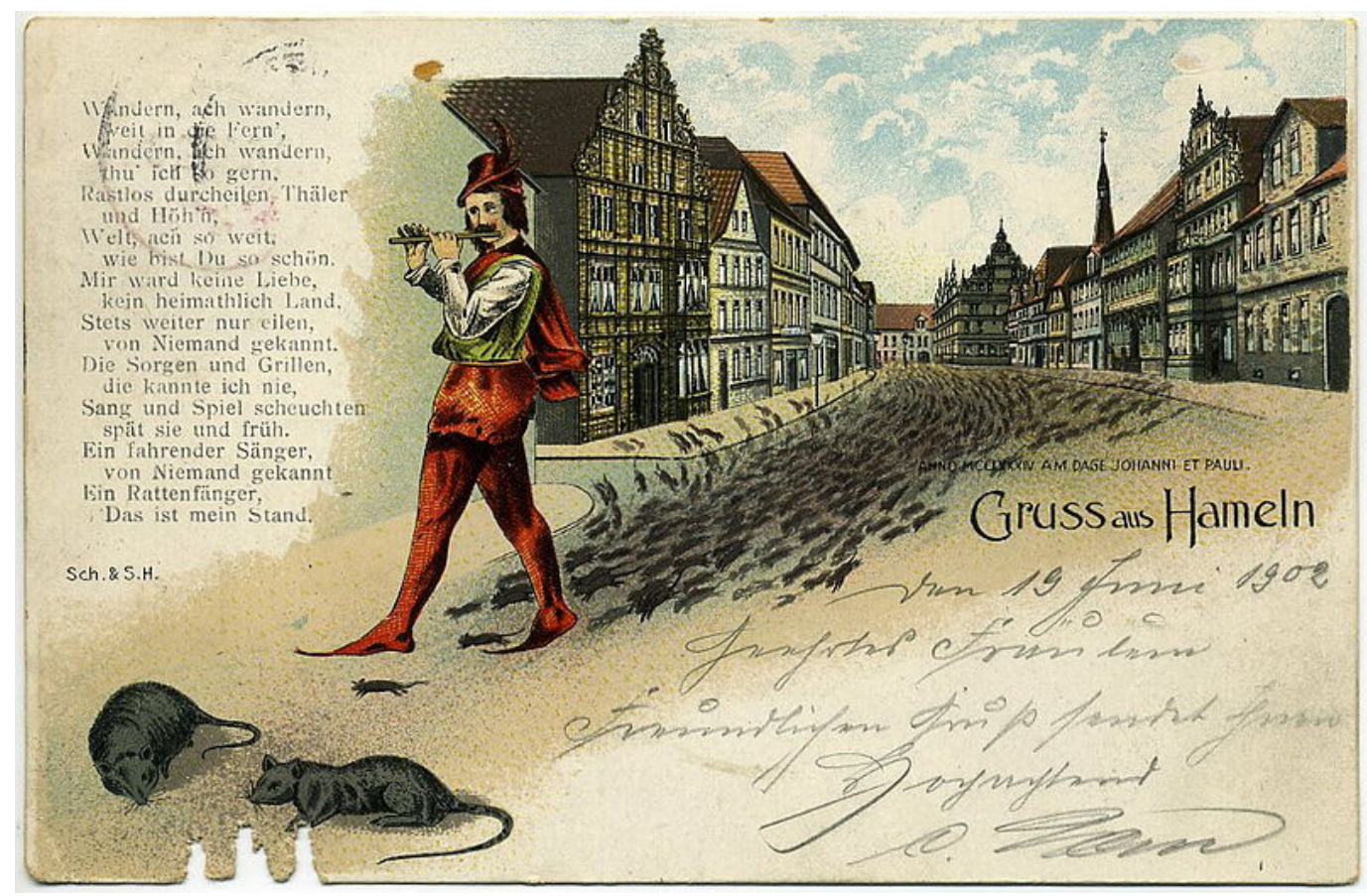




\section{Los roedores en el imaginario cultural}

La primera vez que escuchamos la historia de Hamelin, de niños, nos pareció increíble. Imaginar una fila de ratas siguiendo a un flautista resulta una escena digna de verse, por decir lo menos. Pero en nuestro trabajo de campo como biólogos y, en general, en nuestro andar en esta profesión, hemos escuchado historias sorprendentes acerca de las creencias de la gente sobre ratas y ratones, varias tan creativas como la fábula de Hamelin.

Por ejemplo, una vez oímos que la grasa de las ratas era empleada para freír las papas fritas de una conocida marca comercial. Otras creencias atribuyen a los ratones una naturaleza dual (mitad ratón, mitad murciélago). En una ocasión, en alguna región de la Sierra Madre Occidental, alguien nos contó que los ratones son estados juveniles de murciélagos; y en los Altos de Chiapas complementan esta creencia, al considerar que, cada 31 de diciembre, los ratones hacen su transición a estos mamíferos voladores (ver imagen 2). En los Altos de Chiapas, los ratones y los años, cambian a la par.

Imagen 2. Murciélago. En ciertas poblaciones se cree que los ratones, al crecer, se transforman en murciélagos.

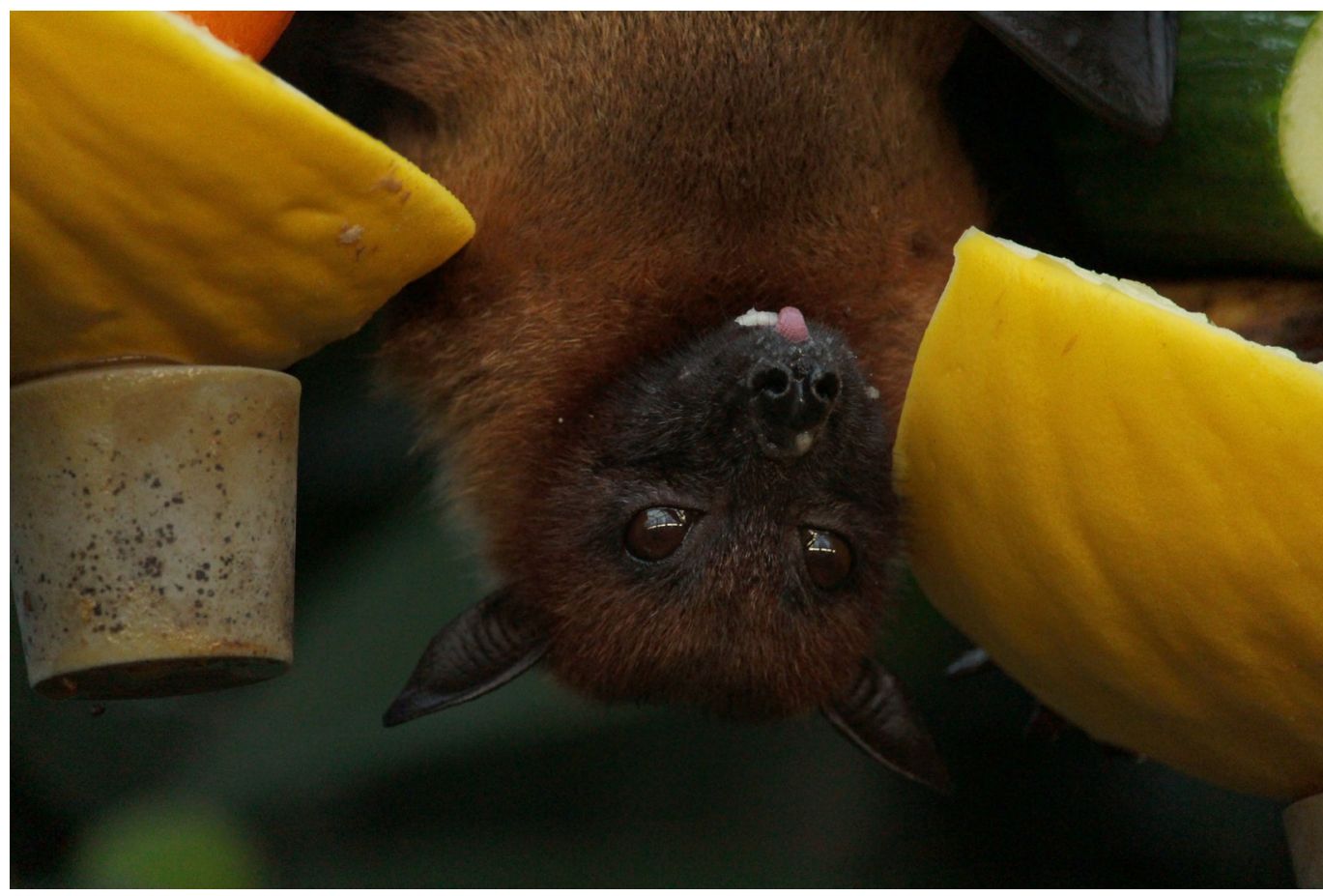

Otros mitos sobre estos pequeños animales nos dicen que son capaces de disolver su esqueleto para pasar a través de pequeños recovecos, o que en las alcantarillas de la Ciudad de México viven las ratas más grandes del mundo.

En definitiva, los roedores son vistos por la mayoría de la gente como animales feos, como una plaga que hay que combatir, portadores de enfermedades y augurios malignos y se les asocia siempre a la suciedad o con sus más terribles pesadillas. Pero, como veremos a continuación, los roedores son mucho más de lo que nos han contado. 


\section{¿Roedores, ratas y ratones?}

Los biólogos, en su afán por comprender mejor la diversidad que nos rodea, agrupan a los animales similares y les asignan un nombre. En este caso, bajo la categoría de roedores se encuentran todos los mamíferos que tienen el hábito de roer, esto es, que desgastan superficies con sus dientes frontales. En esta clasificación entran ratas, ratones, hámsters, cuyos, chinchillas, puercoespines, guaqueques y ardillas (Musser y Carleton, 2005).

Otra manera de clasificar a los roedores, es por su tamaño corporal. De esta manera, cuando un biólogo habla de ratas, se refiere a roedores con un peso entre 200 y 300 gramos. En cambio, cuando habla de ratones se refiere a roedores que pesan de 10 a 50 gramos. Pero cuando habla de roedores, podría estar hablando de hámsters o chinchillas o ratas.

\section{Roedores: mamíferos abundantes, diversos y habitantes del planeta desde hace tiempo}

Los roedores representan el grupo de mamíferos más abundante del mundo, $40 \%$ de todos los mamíferos que se conocen son roedores. En este momento en el planeta habitan 2,277 especies (Han et al., 2015). Los hay de diferentes tamaños, desde los que pesan unos cuantos gramos hasta el roedor más grande, el capibara, que puede pesar más de 50 kg (Kay y Hoekstra, 2008; ver imagen 3).

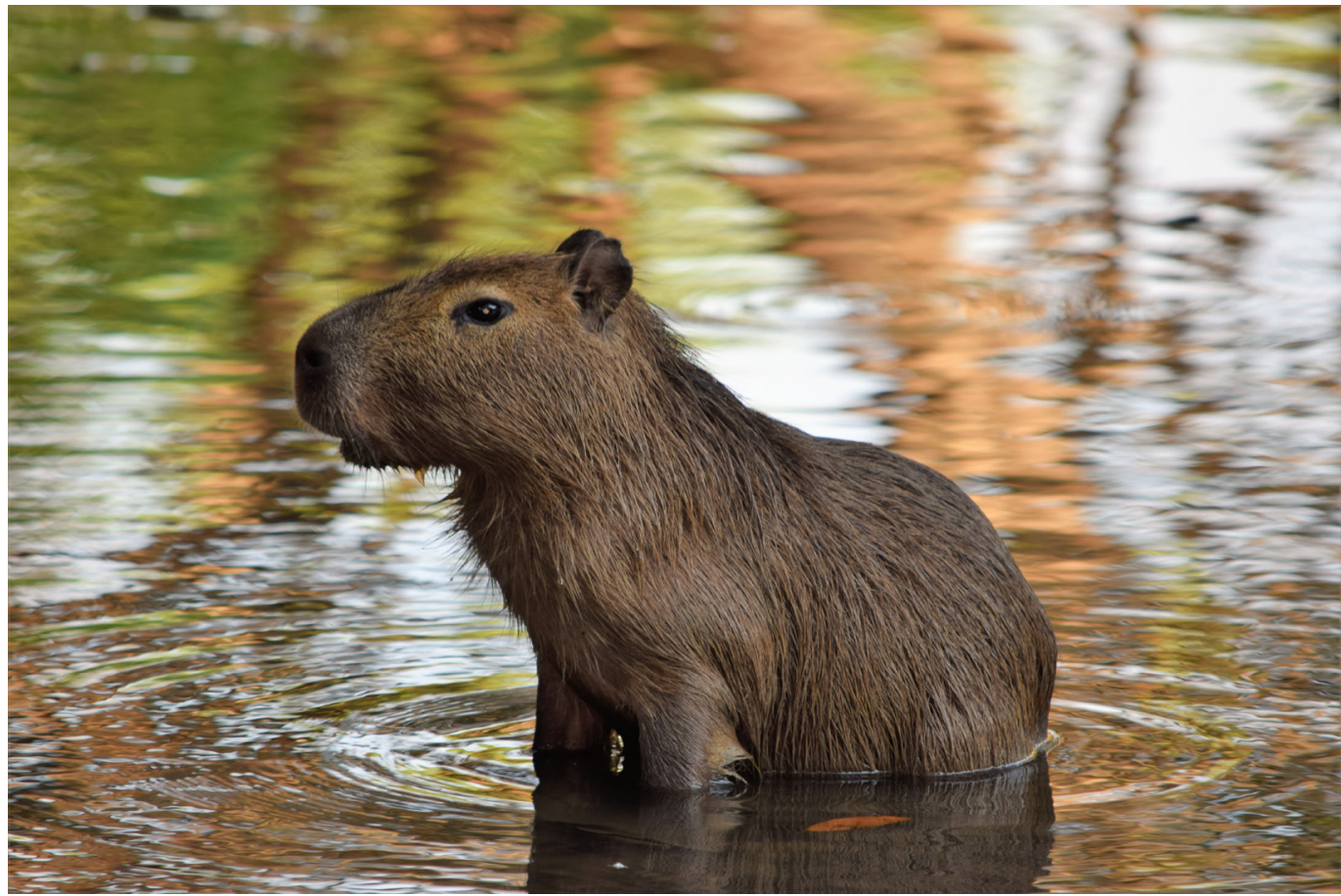


Viven en todos los continentes, excepto en la Antártida. Hay roedores de hábitos semiacuáticos, excavadores, trepadores, saltadores o corredores. Contrario al tan difundido mito de que les encanta comer queso, los roedores prefieren comer una amplia variedad de semillas, hojas, plántulas, frutos y algunos hasta comen insectos, lo que los convierte en omnívoros.

Estos mamíferos existen desde hace unos 20 millones de años. Los primeros roedores vivieron en lo que ahora es Asia y eran parecidos a los actuales, pero algunos eran de enorme tamaño, como es el caso de una especie de roedor que vivió hace unos 3.5 millones, de casi una tonelada de peso y aproximadamente $2.5 \mathrm{~m}$ de largo (casi lo mismo que un auto compacto) cuyo nombre era Josephoartigasi monesi (Kay y Hoekstra, 2008). Afortunadamente para muchas personas, desde entonces y hasta la fecha, los roedores han disminuido su tamaño, pero también se han diversificado mucho.

\section{Roedores chiquitos y grandotes que desempeñan grandes roles}

Son tantas las especies de roedores, que los biólogos han conformado otros dos subgrupos para estudiarlos mejor. A los que habitan casas, alcantarillas y ciudades, les llaman roedores sinantrópicos, que viene de sinantropía, la capacidad de algunos animales de coexistir con los seres humanos y beneficiarse de esta coexistencia (Banks y Smith, 2015). En este grupo estarían las ratas que se encuentran en los basureros, como Remy la rata cocinera de la película de Disney, Ratatouille (ver imagen 4).

Imagen 4. Rata entrenada para permanecer en el hombro de una persona (Servaes, 2006).

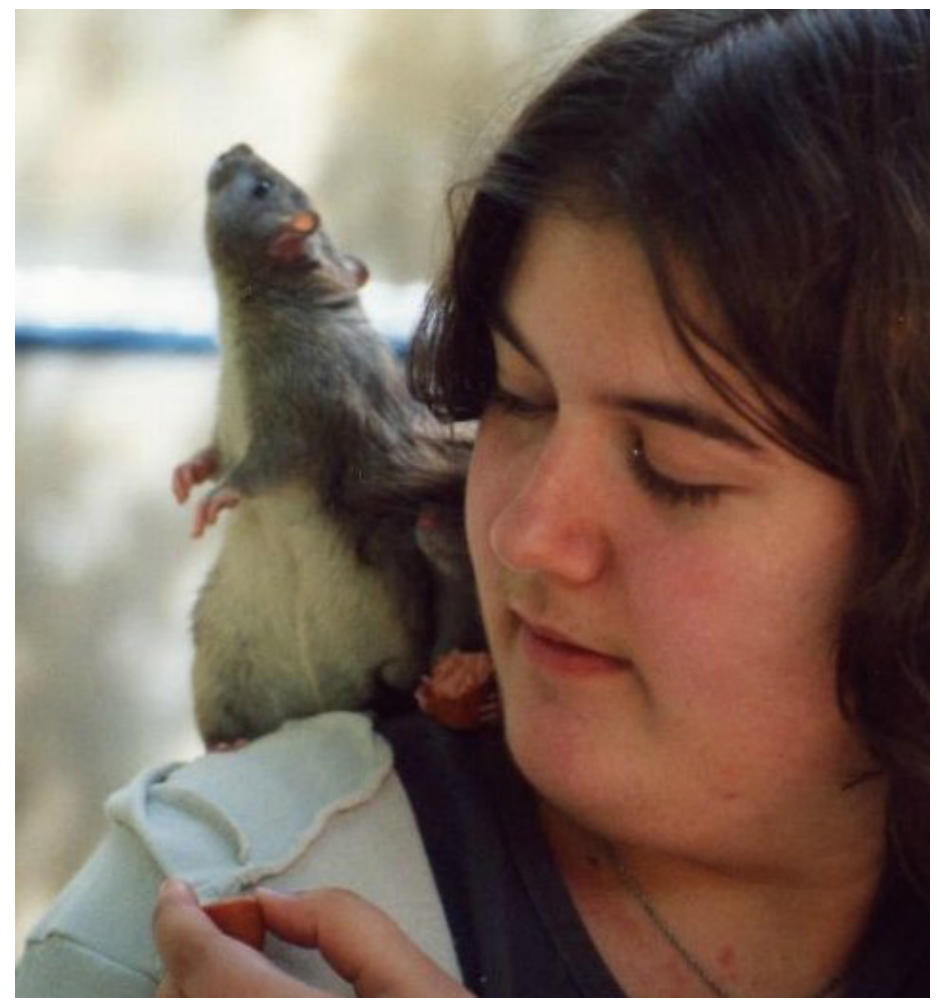


Por otro lado, a los roedores que viven en los bosques, las selvas, los desiertos, la tundra y los pastizales del mundo, les llaman roedores o ratones silvestres. Estos tienen un papel fundamental en la conservación de los ecosistemas que habitan. Por ejemplo, mantienen los bosques con árboles pues al alimentarse de semillas, llevan éstas de un lado a otro abriendo la posibilidad de que puedan germinar y crecer en sitios distantes a donde fueron recogidas. Muchas de estas especies son únicas y su supervivencia está fuertemente ligada a la permanencia de esos lugares.

Mientras que algunos roedores ayudan al mantenimiento de bosques y desiertos, otros juegan un rol en la alimentación y tradición gastronómica de algunas culturas. Puesto que para los seres humanos siempre ha sido menester alimentarse, algunas comunidades han desarrollado el gusto y la necesidad de comer roedores, principalmente silvestres. Pueblos en Ecuador, Perú, China, Tailandia, India, algunos países del Continente Africano y México guardan esa tradición.

En los Altos de Chiapas, por ejemplo, todavía es común ver puestos con ratones listos para comer en algunos mercados de ciertas comunidades (Barragán et al., 2007; ver imagen 5). Pero no únicamente en el sur del país tiene lugar esta práctica, también en el centro-norte. En las áreas semiáridas de Zacatecas, Durango y Tamaulipas, los pobladores locales de áreas rurales consumen varias especies de roedores silvestres grandes, a las que llaman ratas de monte (Valadez Rodríguez, 2017).

Imagen 5. Mercado de San Juan Chamula, en los Altos de Chiapas (Sauber, 2008).

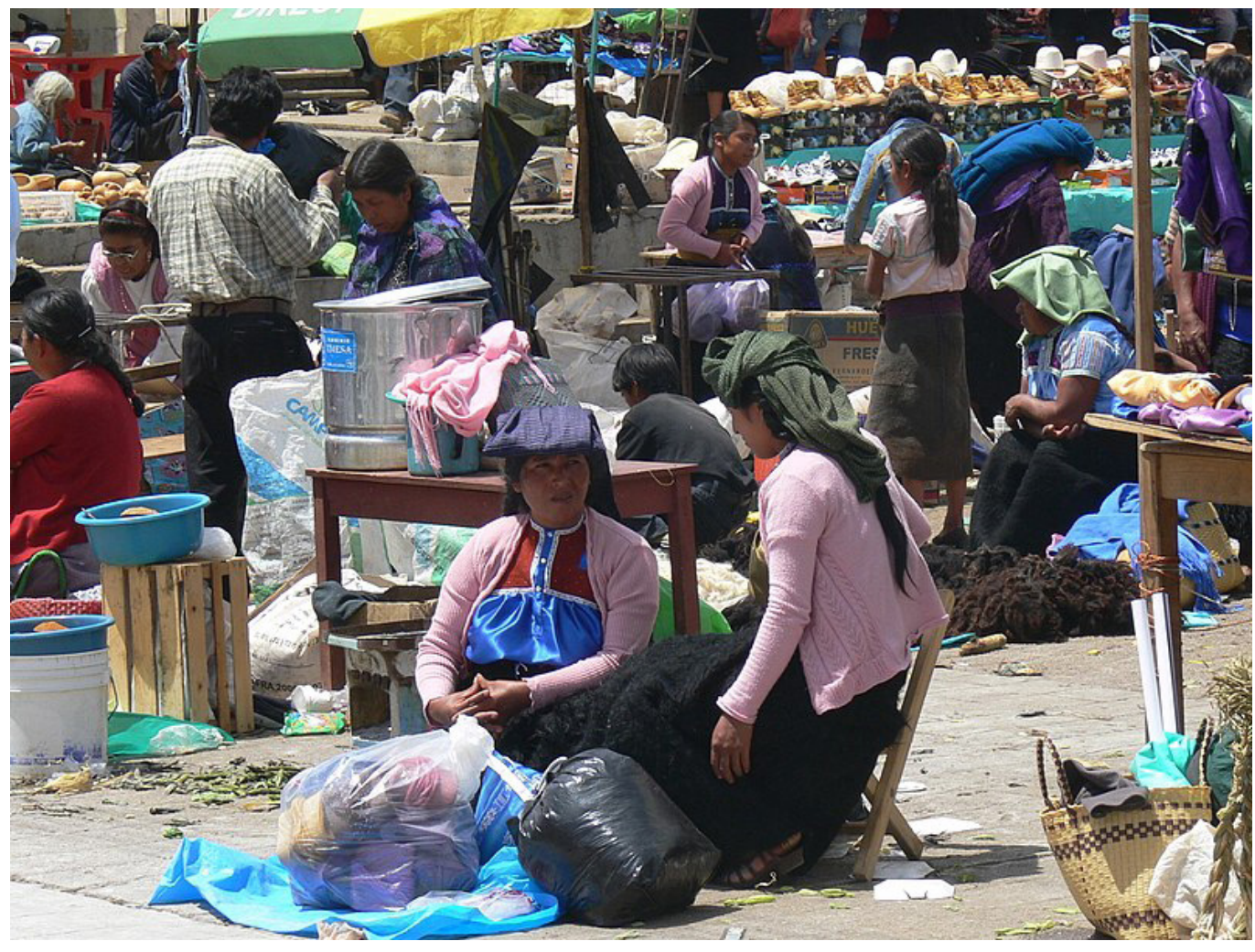


"Flautistas, bagels y tortillas: la vida secreta de ratas y ratones" Gloria Tapia Ramírez y Aarón Hernández Núñez Vol. 22, Núm. 4, julio-agosto 2021 Revista Digital Universitaria

La gente no sólo se come a los roedores, sino que también sabe de sus hábitos (conocimiento necesario para atraparlos) y a partir de ellos les asigna nombre. Por ejemplo, la rata cambalachera, una especie de rata de monte de alto consumo en Zacatecas, recibe su nombre de una acción cada vez menos frecuente: el cambalache. El cambalache refiere a la costumbre de intercambiar un objeto por otro. Estas ratas construyen madrigueras con ramas, hojas, pasto y otra materia vegetal. Con la expansión de los humanos, las ratas cambalacheras encuentran cierta fascinación por los objetos que la gente deja tirados en el camino, sobretodo sin son brillantes.

Se ha documentado que la rata cambalachera puede "intercambiar" una de sus preciadas ramitas para la construcción de su madriguera por un objeto brillante dejado por un excursionista o un campesino, si se lo encuentra en su camino. De esta manera, en las madrigueras no sólo se han encontrado los materiales de construcción típicos, sino también otros, como encendedores, plumas o envolturas de caramelo; que fueron descubiertos por biólogos y pobladores al estudiar e inspeccionar las madrigueras.

\section{Roedores que acompañan a los seres humanos}

Los roedores sinantrópicos, por otro lado, han desempeñado un papel importante en la expansión y conquista de nuevos territorios junto con los humanos. Se trata de especies perfectamente adaptadas a coexistir con nosotros, puesto que les proporcionamos comida y lugares para refugio, por lo que se han vuelto muy exitosas y numerosas (Feng y Himsworth, 2014).

Dentro de las varias especies de roedores sinantrópicos, destacan tres por su asombrosa capacidad para distribuirse por el mundo al seguir a los humanos. Estas son la rata negra (Rattus rattus), la rata de alcantarilla (Rattus norvegicus) y el ratón casero (Mus musculus, ver imagen 6). Las dos primeras son las ratas de tamaño grande a las que se les ve en parques, mercados y en las grandes ciudades. Contrario a lo que se cree, no hay ratas del tamaño de conejos. Quienes estudian ratas de alcantarilla en las grandes ciudades del mundo han demostrado que no llegan a pesar más de un kilogramo (Bradley, 2015); en cambio, un conejo adulto puede pesar más de seis. El ratón casero, como su nombre lo indica, habita sobre todo en las casas de la gente y no supera los 50 gramos (menos de lo que pesa un huevo de gallina).

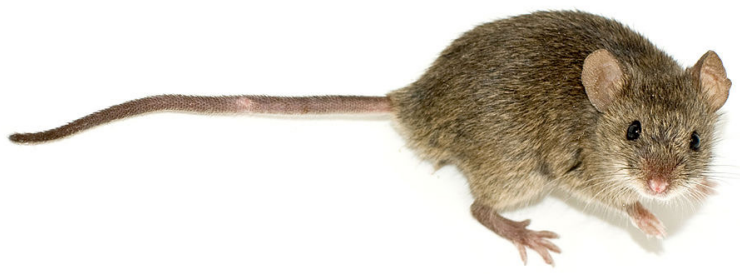


"Flautistas, bagels y tortillas: la vida secreta de ratas y ratones" Gloria Tapia Ramírez y Aarón Hernández Núñez Vol. 22, Núm. 4, julio-agosto 2021 Revista Digital Universitaria

Estas especies habitan en todo el mundo, aunque se originaron en Asia y llegaron a otros continentes e islas viajando en navíos. Una vez que se distribuyeron por todos los lugares habitados, aprendieron a convivir de manera muy estrecha con el ser humano. Estudios recientes con ratas de la ciudad de Nueva York han concluido que incluso su ADN está adaptado para la vida y el estrés de esa ciudad (Harpak et al., 2020). Sucede que después de muchos años y generaciones viviendo en Nueva York, las ratas tuvieron se acostumbraron a comer los desechos de los neoyorquinos, pues éstos eran de más fácil acceso. En las ratas que sobrevivieron comiendo esto, y que desarrollaron "gusto" por ello, se seleccionaron pequeñas y casi imperceptibles diferencias en su genoma, que se transmitieron a su descendencia, y que les han permitido sobrevivir en una ciudad con cantidades descomunales de desperdicios de alimentos ultraprocesados (Harpak et al., 2020).

Parece que, puestas a elegir, prefieren comer un pedazo de pizza o un bagel que las semillas o frutos que comían las primeras ratas silvestres allá en la lejana Asia. Quizá las ratas de México también han adaptado su dieta a una parecida a la de los seres humanos que les proporcionan techo y, por eso, los habitantes del centro de Chiapas refieren que las ratas prefieren tortillas de maíz y plátanos o guineos, como les llama en esta región.

Gracias a la gente interesada en el estudio de las ratas que habitan en las ciudades, sabemos que no "disuelven" su esqueleto, el cual está formado de huesos y cartílago, como el de los humanos. No obstante, sí son capaces de entrar por agujeros y pequeñas grietas porque son animales con cuerpos flexibles que mueven de un lado a otro mientras se deslizan para entrar. Además, "miden" las dimensiones del agujero con sus bigotes, y así deciden si son capaces de escabullirse por el agujero o no (BBC, 2018).

\section{Roedores, ¿causantes de enfermedades?}

¿De dónde proviene la fama de que son portadores de enfermedades? Los roedores en general son portadores de microorganismos que pueden provocar enfermedades en los seres humanos. Una de las enfermedades más conocidas y atribuida a ratas, es la peste negra que ocasionó la muerte de unos 20 millones de personas en Europa durante la Edad Media. Sin embargo, esta enfermedad en realidad es ocasionada por una bacteria (Yersinia pestis) que parasita pulgas, que muchas veces viven asociadas a las ratas.

Podríamos decir entonces que esta enfermedad no es culpa directamente de las ratas, sino de sus pulgas y de las condiciones que incrementan sus poblaciones. Se sabe ahora que las condiciones de insalubridad y hacinamiento en las que vivía la sociedad europea de ese entonces favoreció la presencia de un gran número de ratas, lo que resultó en el caldo de cultivo perfecto (esto es que todas las condiciones eran propicias) para el surgimiento de la peste negra (Bramanti et al., 2016). 
Imagen 7. Traje típico que se usó durante la peste negra.

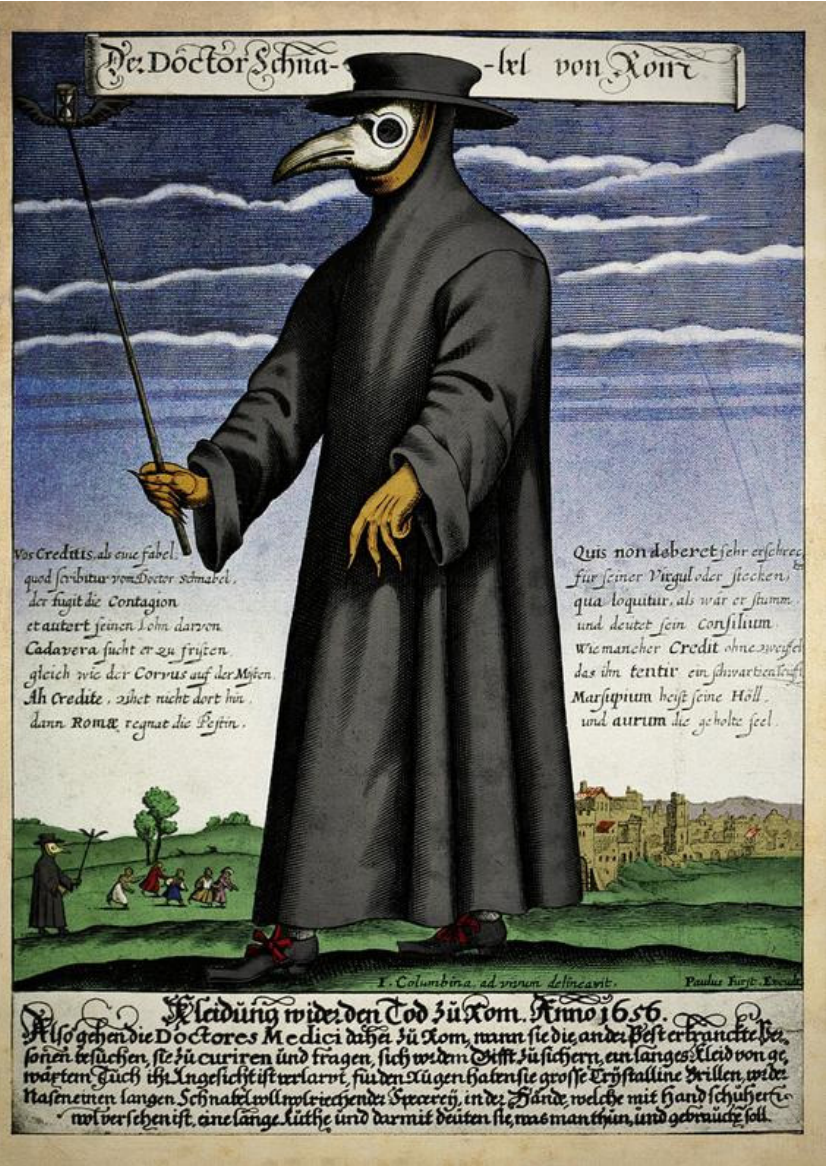

Sin embargo, hace un par de años se puso en duda el papel que desempeñaron las ratas en la diseminación de la peste negra y se ha propuesto que los responsables fueron los piojos de los humanos, que por aquel entonces eran muy abundantes, pues se tenían condiciones higiénicas diferentes (Dean et al., 2018).

Ya en la era moderna, otras enfermedades producidas por hantavirus y arenavirus, han sido atribuidas a los roedores silvestres (Han et al., 2015). Nuevamente, no son propiamente los roedores quienes ocasionan las enfermedades, sino más bien los virus o las bacterias que portan. Varios estudios proponen que cuando los seres humanos destruyen el hábitat de los roedores, éstos buscarán abrigo y alimento en nuestras casas, cultivos o granjas. De esta manera, humanos y roedores silvestres entran en contacto, favoreciendo la posibilidad de que los virus y bacterias de los ratones pasen y enfermen a los humanos (Daszak, Cunningham y Hyatt, 2000). Los roedores son reservorios de virus desde sus orígenes, por esta razón ellos no enferman, pero nosotros sí. Así, se tiene una responsabilidad compartida con ellos, pues es el ser humano quien ha favorecido su presencia y cercanía. Algo como lo que ocurrió con la pandemia debida a la covid-19, pero con otra especie animal. 
"Flautistas, bagels y tortillas: la vida secreta de ratas y ratones"

Gloria Tapia Ramírez y Aarón Hernández Núñez

Vol. 22, Núm. 4, julio-agosto 2021

Revista Digital Universitaria

\section{Ratasy ratones: presentes constantemente no sólo en fábulas}

Hemos hablado del halo casi maligno que rodea a los roedores y el papel que desempeñan en los ecosistemas y en aspectos de salud. Sin embargo, hay que decirlo, los roedores han ayudado a que la ciencia avance enormemente. Muchos medicamentos, procedimientos médicos y vacunas se prueban primero en ratas de laboratorio, de manera previa a otros mamíferos y mucho antes de que lleguen a las farmacias.

Pero no sólo eso, los humanos también han aprendido a usar las habilidades de los roedores silvestres para nuestro beneficio. Por ejemplo, hace un par de años varios medios de comunicación dieron a conocer la noticia de que en África estaban usando ratas gigantes (Cricetomys gambianus) entrenadas para detectar minas antipersonales, para que así fueran desactivadas antes de que pudieran dañar a un ser humano (Poling et al., 2010). Usaban estas ratas porque pesan lo justo como para ser capaces de pararse sobre las minas y no activarlas. Recientemente, también en África, se han entrenado ratas que pueden detectar a personas con tuberculosis sólo con olerlas, lo que ayuda a registrarlas y tratar de curarlas (Cengel, 2014).

Por estas y otras razones, los roedores resultan fascinantes. Es importante cobrar consciencia de que compartimos el planeta no sólo con grandes mamíferos, sino también con los pequeños. Nuestro desmedido consumo y nuestra rapacidad sobre los ecosistemas hacen que llevemos a unas especies a la extinción -tal como el flautista llevaba a las ratas al río-, pero también favorecemos la abundancia de otras especies de roedores que ponen en riesgo la salud humana. Nosotros -igual que el flautista- podríamos conducir a la humanidad a un futuro incierto. Aprendamos a conocer y a respetar a las especies que nos rodean y los ecosistemas que habitan.

\section{Referencias}

* Banks, P. B. y Smith, H. M. (2015). The ecological impacts of commensal species: Black rats, Rattus rattus, at the urban-bushland interface. Wildlife Research, 42(2), 86-97. https://doi.org/10.1071/WR15048

* Barragán, F., Retana, O. G. y Naranjo, E. J. (2007). The rodent trade of tzeltal indians of Oxchuc, Chiapas, Mexico. Human Ecology, 35(6), 769-773. https://doi. org/10.1007/s10745-007-9116-7

- BBC. (2018). ¿Cómo logran doblarse los ratones para pasar por huecos muy pequeños? https://www.bbc.com/mundo/media-42866453

Bradley, R. (2015). The rat paths of New York. The NewYork Times Magazine. https:// 
"Flautistas, bagels y tortillas: la vida secreta de ratas y ratones" Gloria Tapia Ramírez y Aarón Hernández Núñez Vol. 22, Núm. 4, julio-agosto 2021 Revista Digital Universitaria

www.nytimes.com/2015/04/26/magazine/the-rat-paths-of-new-york.html

- Bramanti, B., Stenseth, N. C., Walløe, L. y Lei, X. (2016). Plague: A disease which changed the path of human civilization. Advances in Experimental Medicine and Biology, 918, 1-26. https://doi.org/10.1007/978-94-024-0890-4_1

- Cengel, K. (2014). Giant Rats Trained to Sniff Out Tuberculosis in Africa. National Geographic. https://cutt.ly/qnxoqRI

* Daszak, P., Cunningham, A. A. y Hyatt, A. D. (2000). Emerging Infectious Diseases of Wild life-Threats to Biodiversity and Human Health. Science, 287(5452), 443-449. https://doi.org/10.1126/science.287.5452.443

* Dean, K. R., Krauer, F., Walløe, L., Lingjærde, O. C., Bramanti, B., Stenseth, N. C. y Schmid, B. V. (2018). Human ectoparasites and the spread of plague in Europe during the Second Pandemic. Proceedings of the National Academy of Sciences of the United States of America, 115(6), 1304-1309. https://dpoi.org/10.1073/ pnas.1715640115

* Feng, A. Y. T. y Himsworth, C. G. (2014). The secret life of the city rat: A review of the ecology of urban Norway and black rats (Rattus norvegicus and Rattus rattus). Urban Ecosystems, 17(1), 149-162. https://doi.org/10.1007/s11252-013-0305-4

Grimm, J. y Grimm, W. (2000). Leyendas alemanas. Ediciones Obelisco.

* Han, B. A., Schmidt, J. P., Bowden, S. E. y Drake, J. M. (2015). Rodent reservoirs of future zoonotic diseases. Proceedings of the National Academy of Sciences, 112(22), 7039-7044. https://doi.org/10.1073/pnas.1501598112

Harpak, A., Garud, N., Rosenberg, N. A., Petrov, D. A., Combs, M., Pennings, P. S. y Munshi-South, J. (2020). Genetic adaptation in New York City rats [preprint]. BioRxiv. https://doi.org/10.1101/2020.02.07.938969

Kay, E. H.y Hoekstra, H. E. (2008). Rodents. Current Biology, 18(10), 406-410. https:// doi.org/10.1016/j.cub.2008.03.019

* Musser, G. G. y Carleton, M. D. (2005). Superfamily Muroidea. En D. E. Wilson y D. M. Reeder (Eds.), Mammal Species of the World A Taxonomic and Geographic Reference (3a ed., pp. 849-1531). Johns Hopkins University Press.

* Poling, A., Weetjens, B. J., Cox, C., Beyene, N., Bach, H. y Sully, A. (2010). Teaching Giant African Pouched Rats to Find Landmines: Operant Conditioning With Real Consequences. Behaviour Analysis in Practice, 3(2), 19-25. https://doi.org/10.1007/ BF03391761

- Sauber, W. (2008, 18 de marzo). [San Juan Chamula (Chiapas)]. Wikimedia Commons. https://commons.wikimedia.org/wiki/File:San_Juan_Chamula___Markt_6.jpg

- Servaes, J. (2006, 10 de julio). [Rata entrenada para permanecer en el hombro de una persona]. Wikimedia Commons. https://commons.wikimedia.org/wiki/File:Rat_ shoulder.jpg

- Shuklin, G. (2008, 24 de noviembre). Mus musculus. Wikimedia Commons. https:// cutt.ly/dnxd6m7 
"Flautistas, bagels y tortillas: la vida secreta de ratas y ratones" Gloria Tapia Ramírez y Aarón Hernández Núñez

Vol. 22, Núm. 4, julio-agosto 2021

Revista Digital Universitaria

* Valadez Rodríguez, A. (2017). Caldo de rata, el platillo que levanta muertos. La Jornada. https://www.jornada.com.mx/2017/06/25/estados/025n1est

\section{Cómo CITAR ESTE ARTículo}

* Tapia Ramírez, Gloria y Hernández Núñez, Aarón. (2021, julio-agosto). Flautistas, bagels y tortillas: la vida secreta de ratas y ratones. Revista Digital Universitaria (RDU), 22(4). http://doi.org/10.22201/cuaieed.16076079e.2021.22.4.5 